\title{
González Martínez y la crítica
}

Vamos a mencionar y comentar los trabajos de los críticos que han dedicado estudios a gran parte de la obra lírica de González Martínez o que han contribuído con su agudeza a la crítica del "Hombre del Buho". Algunos, como Roberto Avrett y Luisa Luisi, sólo han estudiado un aspecto de su obra y por eso los estudiamos aparte. Otros, como Manuel Toussaint y Antonio Castro Leal, han hecho estudios detallados de la obra inicial del poeta. Otro grupo hizo estudios que aunque constituyen homenajes no dejan de tener gran valor; entre ellos se cuentan Luis G. Urbina y Enrique DíezCanedo. Con esto queremos indicar que no hay estudios completos y especialmente que tengan que ver con la poesía reciente del poeta, la más lírica. La mayoría son artículos que se han publicado como prólogos a determinadas ediciones o como conferencias. Queremos probar que hace falta un estudio completo y general sobre la obra de González Martínez.

En la cuarta parte reseñamos los juicios que traen algunos manuales de literatura y antologías. La mayoría de ellos revela el prurito de ser fieles a la tradición de repetir una crítica cristalizada hace muchos años, sin tomar en cuenta las nuevas contribuciones de González Martínez.

Otro propósito de este estudio ha sido el de apuntar que el interés en la obra de González Martínez siempre ha estado vivo. La razón es evidente. Como Benavente en el prólogo a sus obras completas, puede decir el Hombre del Buho que se ha comido más de dos generaciones de críticos. La obra de González Martínez, 'que abarca desde fines del siglo xix hasta el presente, también ha sobrevivido a dos generaciones de críticos. Existe además, por parte de varios de esos críticos, un voluntario alejamiento de la obra 
de un poeta que ha tenido la valentía de seguir sus propias tendencias estéticas; olvidan que la mayoría de los grandes poetas ha rebasado toda clasificación retórica.

\section{ESTUDIOS GENERALES}

Frances Benge. La señorita Frances Benge hizo en diciembre de 1924 un estudio que publicó la Facultad de Altos Estudios de la Universidad de México titulado "La biografía lírica de Enrique González Martínez. ${ }^{1}$ Es un esfuerzo de comprensión que incluye la obra total del poeta hasta El romero alucinado. Basándose en la crítica anterior se ocupa de los siguientes temas: el amor al silencio, la depuración constante del poeta, el panteísmo, el lirismo dramático, el dolor, el simbolismo y el humorismo.

La señorita Benge apunta esos temas y declara que el doctor González Martínez es "E1 primer poeta" y además "E1 poeta actual de la América Latina". El estudio es de tipo impresionista, carece de bibliografía y la documentación nos parece incompleta.

Antonio Castro Leal. Antonio Castro Leal ha incluído en su edición de 1946 los cuatro primeros libros de González Martínez, ${ }^{2}$ un prólogo en el cual estudia con algún detalle las influencias y el desarrollo del poeta, en el cual concede a los temas cuidadosa atención. Trata del misticismo y el panteísmo de González Martínez y agrega a la crítica martiniana la frase "apasionado existencialismo", a lo que otros críticos llaman su "vitalismo". La contribución de Castro Leal es además valiosa por el esmero de la edición de estos cuatro primeros libros y especialmente de Preludios y Lirismos que nos da en un texto primoroso y asequible de poemas que el poeta mismo había desechado, y también anota las variantes hechas por el poeta. Todo ello es de sumo interés para el estudio del desarrollo y el método de depuración de González Martínez.

Pedro Henriquez Ureña. En 1927 Pedro Henríquez Ureña amplió un estudio escrito en 1915 sobre González Martínez. ${ }^{3}$ Es una crítica de gran penetración y belleza. Este estudio ha sido muy leido y citado. En nota subsecuente sitúa a González Martínez como poeta de actualidad en 1917 y limita su influencia hasta 1922. Men- 
ciona el simbolismo del poeta y trata de la cuestión del cisne y el buho, del tema del silencio, del dolor y del afán de renovación.

Al tratar del simbolismo del dolor, nos da un interesante vislumbre acerca de lo que debe ser el verdadero simbolismo:

El poeta piensa que debe "llorar, si hay que llorar, como la fuente escondida"; debe purificar el dolor en el arte, y, según su religión estética, trasmutarlo en símbolo. Más aún: el símbolo ha de ser catharsis, (sic) ha de ser enseñanza de fortaleza. 4

Acerca de la autobiografía lírica de González Martínez declara Henríquez Ureña lo que el tiempo ya ha aceptado y muchas veces se ha citado:

La autobiografía lírica de Enrique González Martínez es la historia de una ascención perpetua. Hacia mayor serenidad; pero a la vez hacia mayor sinceridad; hacia más severo y hondo concepto de la vida. Espejo de nuestras luchas, voz de nuestros anhelos, esta poesía es plenamente de nuestro siglo y de nuestro mundo. 5

Alfonso Reyes. Alfonso Reyes, agudeza y arte de ingenio, dedicó unas páginas a González Martínez, en el prólogo a Los senderos ocultos publicado en 1918. ${ }^{6}$ Es estudio bien conocido y constantemente citado. Descifra en su manera fascinadora muchos de los misterios del Buho.

Acerca de la continuidad de la obra de González Martínez dice:

Y no porque de Silenter a Los senderos ocultos haya que salvar gran trecho: el poeta labora con una preciosa constancia, y puede asegurarse que en el instante que se dobla la hoja del libro anterior se abre la del siguiente. 7

A la critica del misticismo del Buho, agrega ciertas frases e ingeniosos conceptos. Al hablar de la musa del poeta declara que no tiene creencias ni sed religiosa. Postula como nombre de este misticismo la frase de misticismo abstracto. Estas son sus razones:

Trátase, en efecto, de un misticismo sin creencia, aunque aquí la alegoría pagana no debe ser entendida en estricto sentido: la poesía de González Martínez nunca pudo ser sinceramente pagana. En pasados siglos habría hecho su nido, como golondrina, en el madero de la cruz; más tarde habría llorado 
su misma carencia de fe, según cierta moda romántica. Mas tal actitud, para la honesta veracidad de este poeta, resultaría forzada, y así — sello verdaderamente contemporáneo-, su musa se nos muestra sin fe religiosa, pero también sin sed religiosa; $y$ de los bajos estímulos del sentido, como la satiresa; asciende, en su misticismo abstracto, hacia una adoración del silencio y la soledad por influencia del demonio interior (iea!) es ya tiempo de innovar la fórmula, del Sócrates interior que todos llevamos. 8

Después, en un suspiro poético, califica Reyes a este misticismo como un "misticismo del alma por el alma", y lo acepta como en la tradición de Plotino:

¡Oh, vida paciente! Nadie sabe la estrella que esta nebulosa nos previene. Es verdad: ya no podemos ser místicos a la antigua manera, a la manera heroica, y ya no se apoya el misticismo en la cruz. Aquél, aun cuando no fuera del arte su principal fin, dejaba correr, desde las cumbres del éxtasis, ríos hirvientes de belleza. Pero este nuevo misticismo del alma por el alma misma, no limitado por doctrina alguna, menos exaltado que el otro, menos agudo; que nos arroja al hombre de sí -antes lo mantiene en su centro-, y es casi condición del humor, y sé hace normal y cotidiano, puede ser también más seguro y estable: Plotino escribió que nuestra alma, tocando a las esferas de lo absoluto, retrocede como espantada y sólo puede gustarlo por intermitencias. 9

Sobre el paganismo de González Martínez, del cual trataremos a su tiempo, escribe, "le siento un poco débil cuando ensaya imágenes paganas", porque, "no pertenece a la clase de los poetas helenistas..." Pero al apuntar los símbolos tan originales de González Martínez y especialmente a "los minúsculos detalles, ricos de observación directa", le declara más cercano a los griegos. ${ }^{10}$

También apunta Alfonso Reyes la nota franciscana en la poesía de don Enrique:

halagaban mi oído las voces de las aves,

la balada del viento, el canto del pastor.

Y quitarás piadoso tus sandalias $\mathbf{1 1}$

Por no herir a las piedras del camino. 
Y acerca de la nota en sordina en su poesía dice:

Y por último, ni siquiera falta la nota en sordina de la poesía, cotidiana y semihumorística, en que se revelan los verda. deros poetas, los que dejan fluir belleza de sí hasta en la fácil manera de la conversación. 12

Manuel Toussaint. Bajo el título de "Evolución poética de Enrique González Martínez", Manuel Toussaint dedicó uno de los mejores y más detallados estudios, al publicar la selección de poesías titulada Poemas escogidos en 1917. ${ }^{13}$ Aquí sólo se apuntan los rasgos salientes del estudio. Hablaremos con más amplitud sobre este estudio, al tratar de la obra inicial de González Martínez $y$ del problema de las influencias.

Como la mayoría de todos los estudios, está limitado por su fecha, 1917. Trata de Preludios y Lirismos con mucho detalle. Señala Manuel Toussaint, en Silenter, la formación del mundo interior del póeta:

Acerca del misticismo trata a González Martínez como a un contemplativo y llama al producto de ese sentimiento que él denomina hipertrofia sensitiva, lirismo abstracto. Discute el afán vitalista del poeta basándose en la escuela contemporánea francesa.

Considera Toussaint a González Martínez como poeta moderno, por su gran inquietud ante los problemas del tiempo. Atribuye también un valor poético a su hondura filosófica declarando que sus obras posteriores a 1918 son ya trabajo de madurez.

Al hablar de la inquietud de González Martínez, apunta el crítico una interesante idea de la trascendencia de su arte, "o la referencia a la poesía desde el punto de vista de poeta, es decir, ocuparse en ella... hoy exclama el poeta:

"Escribe de la hora, mas no para la hora".

Y después agrega: "en un poema lleno de fe en que lo inesperado da al artista un segundo de inspiración para cincelar el verso único con el cual, a pesar de la indiferencia humana, del desdén que 'es ciego a sus visiones y sordo a su dolor', puede supervivir al olvido."

Quizás entre la angustia.que colma el universo por excepción atines en una nota fiel y hagas un verso sólo,... Mas sabe que ese verso prolongará tu espíritu, y vivirás en él. 14 
Notamos esta idea por el paralelismo espiritual de muchos escritores modernos tales como Unamuno, que ante el sentimiento trágico del escepticismo moderno y la sed de religiosidad han descubierto su inmortalidad en su obra artística.

\section{ESTUdIOS SOBRE EL MISTICISMO DE GONZALEZ MARTINEZ}

Además de los escritores mencionados que han tratado del misticismo de González Martínez, hay otros estudios dedicados solamente a la fase filosófica o al misticismo.

Robert Avrett. En 1931 Robert Avrett publicó en Hispania el resumen de una tesis que presentó en la Universidad de Texas en junio de 1928, con el título de "Enrique González Martínez, -Philosopher and Mystic". ${ }^{15}$ En esta sintesis apuntó las tendencias filosóficas y místicas de González Martínez. El estudio es limitado porque incluye sólo la obra de González Martínez hasta Las señales furtivas (1925). Apoyándose en las críticas de Eduardo Colín, Luisa Luisi y Suárez Calimano, ${ }^{16}$ a quienes mencionaremos al hablar del misticismo de González Martínez, Avrett apunta la tendencia filosófica basada en el temperamento y no en la versificación de temas filosóficos. La definición del misticismo de González Martínez no es muy clara y no coincide con la que propone en este estudio, apoyada por el mismo González Martínez. ${ }^{17}$

\section{ESTUDIOS DE HOMENAJE}

No obstante que son de homenaje no carecen estos estudios de rigor crítico e importancia estética. Son una verdadera contribución a la crítica de González Martínez.

Enrique Diez-Canedo. Enrique Díez-Canedo ha dedicado varios estudios ${ }^{18}$ a Enrique González Martínez. Existió entre los dos poetas una afinidad, por coincidencias de temas en su obra lírica, que los llevó a una amistad estrecha. En "El Cóndor, el Cisne y el Buho" trazó Díez-Canedo el imperio de esta trilogía simbólica en la literatura española e hispanoamericana (basándose en una idea de Alfonso Reyes), y agregando otra nota a esa cuestión del cisne y el buho. 
En este mismo articulo marcó Díez-Canedo la transición de la poesía de González Martínez, del parnasianismo a una percepción fervorosa de la realidad. Observa la perfecta continuidad de la obra lírica, ya observada por Alfonso Reyes, y la plenitud en su obra desde La muerte del cisne hasta El romero alucinado. De interés para nosotros es su idea del estoicismo de González Martínez. "La clave de la melodía es una serenidad trágica: la serenidad del estoico. Ser hombre: delicia y tortura a la vez". ${ }^{19}$

En el segundo artículo, publicado en la Revista Iberoamericana en 1940, dedicó otro estudio al segundo tomo de las Obras de don Enrique, el cual contiene desde Parábolas y Otros poemas (1918) hasta Las señales furtivas (1925).

Apuntó en este artículo el anhelo dantesco de algunas poesías, en que se evoca las sombras del pasado; el desarrollo de la métrica, de una actitud clásica al uso de combinaciones modernas; y advirtió el paso lento y gradual de una actitud severa y majestuosa a otra más familiar, en que hasta la métrica gusta de aceptar ritmos juguetones, andaduras rápidas, juegos de pies quebrados y rimas traviesas, asuntos frívolos, imaginaciones aventureras: todo ello sin perder la gracia esencial de la serenidad humana. El tercer artículo citado es una refundición de los dos anteriores.

Isaac Goldberg. En su libro Studies in Spanish-American Literature, ${ }^{20}$ Isaac Goldberg habla de la influencia de la disciplina científica de González Martínez, como un factor en la reacción contra la poesía modernista, en el poema "Tuércele el cuello al cisne..." Compara esta actitud a la de Verlaine en su "Art poétique". ${ }^{21}$ Acerca del panteísmo de González Martínez dice: "His pantheism is a much wonder as worship; as much inquiry as implicit belief". ${ }^{22} \mathrm{Y}$ luego le llama un "intellectual pantheist". Nota Goldberg también que la soledad de González Martínez no es la reclusión de un ermitaño que huye del mundo, sino la de un espíritu que se ha adelantado a sus compañeros.

Luis G. Urbina. Luis G. Urbina conoció a González Martínez en 1905, y después trabajaron juntos en tareas periodísticas. En su libro La vida literaria de México Urbina habla de la primera época de su amistad y del panteísmo de González Martínez. Y acerca de la obra de juventud del poeta, en provincias, acertadamente dice: 
"González Martínez, médico de provincia, autoridad de pueblo, se rozaba a diario con la existencia trivial de aldeas y cortijos. Mas por un esfuerzo psíquico que sólo pueden hacer las vidas superiores, realizaba ese inexplicable desdoblamiento, gracias al cual el hombre queda en tierra explicando su actividad material en los menesteres cotidianos y el alma sube, como un celaje, a las alturas del azul profundo de la belleza y la contemplación. ${ }^{23}$

Esa frase, "inexplicable desdoblamiento", nos interesa porque describe la aptitud del artista de superar las vulgaridades de su ambiente.

En la vida literaria, 1917, prometió Urbina un estudio más completo. Años después, en Madrid, cumplió en parte su promesa, en un prólogo a Las señales furtivas, estudio de tipo impresionista en el que recterda la segunda época de su amistad, cuando hicieron juntos obra periodística en México.

Exaltó en este prólogo las cualidades filosóficas, simbolistas, líricas y humorísticas de González Martínez. Al clasificar su filosofía, le llama "emotivo filosófico", "fuerte imaginativo" y "sensitivo extraordinario". Como simbolista le declaró "el más alto, por la incesante elevación del símbolo". Como lírico le dió el máximo lugar: "Sí: no hay en nuestra lírica poeta más alto que González Martínez". ${ }^{24}$ Y como humorista le clasificó como poseído de una piadosa ironía. Dice acerca de su humorismo:

La ha invadido (a su poesía) una ironía piadosa. Una burla exquisita juguetea, intencionalmente, con el símbolo, y lo empuja, por instantes, hasta los límites de lo grotesco trascendental. Los símiles adquieren una gracia, por lo espontánea, casi infantil. Son caricaturas humoristicas, traviesos dibujos del regocijo, diseñados en el vidrio del ensueño. Hay alegría de vivir. 25

\section{MANUALES DE LITERATURA}

R. Blanco Fombona. El agudo y a veces vitriólico Blanco Fombona incluyó a González Martínez entre los modernistas, en su libro El modernismo y los poetas modernistas. ${ }^{26}$ Asignó a González Martínez el papel de "puerta divisoria" entre el modernismo y "lo que viene después". Y sin apuntar ninguna cualidad poética mencionó 
La muerte del cisne, con el augurio para el ave simbólica de Rubén Darío. Su interpretación de La muerte del cisne es de renovación literaria :

Vengan simbolos para la sensibilidad y la inteligencia. Vengan inteligencias y sensibilidades nuevas, parecía decir el autor. Los votos se cumplieron. El buho vivió poco. Los que llegaban, los nuevos poetas, mataron el pájaro de Minerva y del señor González Martínez. 27

Carlos González Peña. Carlos González Peña en su Historia de la literatura mexicana ${ }^{28}$ da una completa nota bibliográfica y biográfica, y cita la muy repetida síntesis de su poesía por don Francisco A. de Icaza, que reproducimos in toto:

Ductilizó su propio verso en la perfecta interpretación castellana de los poetas extranjeros más contradictorios: Lamartine, Poe, Heredia, Francis Jammes, Samain; y llegó a lograr esa técnica que distingue hoy su poesía, original del todo, sabia en el mecanismo de la expresión. La poesía de González Martínez es panteísta. Hay un panteísmo que al divinizar al mundo le adora, adorándose en él. Hay otro que al divinizar la naturaleza la ama devotamente hasta en lo más humilde: ése es el de González Martínez. Optimista, melancólico, siente lo pasajero del dolor, que en la vida normal es tan fugitivo como el placer, y canta ambos, pasados ya, con vaga ternura melancó lica, pues para el poeta no es el dolor tremendo huésped, sino caminante que posa en su hogar, y que mañana al rayar el día, sacudiendo su sandalia, partirá de nuevo. 29

Hacemos hincapié en la frase "optimista melancólico", de gran valor descriptivo, pero a nuestro parecer no adecuada a las actitudes optimistas y al dolor de González Martínez. Su definición del panteísmo del poeta nos parece exacta. Es la misma que Alfonso Reyes llama la actitud franciscana en su poesía.

Julio Jiménez Rueda. Jiménez Rueda señaló en su acertado libro sobre La literatura mexicana del siglo XIX ${ }^{30}$ la excepcional calidad lírica de González Martínez. Menciona su evasión del mundo exterior amado por los modernistas y sus tendencias hacia lo interno, lo substancial, la compostura, la elegancia señorial, la hondura filosófica. Le pone en primera fila como poeta lírico: 
Dolorosísimas pérdidas, la muerte de su esposa y la de su hijo, poeta también. Enrique González Rojo (1899-1939). han llevado a su poesía notas de una grandeza y de una profundidad alcanzada difícilmente por ningún contemporáneo. 31

Para nosotros es muy importante esta cita, por estar de acuerdo con nuestra tesis de la ubicación de González Martínez en la lírica hispanoamericana contemporánea.

Alfred Coester. El crítico Alfred Coester, tan apreciable por su espíritu innovador, en sus notas a su Anthology of the Modernista movement in Spanish America menciona la consabida referencia al poema "Tuércele el cuello al cisne..." y declara: "His verses were of a decided serious type". Lo cual es cierto; pero hay que hablar también del anverso: del humorismo de González Martínez. Sin embargo, agrega una nota de sumo valor, acerca de la actitud de los poetas mexicanos hacia la naturaleza; que se puede aplicar al poeta :

There is something quite Mexican in the mystical attitude towards nature. It appears continuously in Mexican poetry. Perbaps it is the same Andalusian temperament represented by the Spanish modernista poets. Antonio Machado and Juan Ramón Jimenez, who felt that every landscape is a state of mind. 33

Federico de Onis. El medallón que incluyó Federico de Onís en su monumental Antología de la poesía española e hispanoamerica$n a^{34}$ sobre González Martínez, es de los más acertados y completos, aunque no menciona su obra posterior a 1923. Al hablar del mundo interior del poeta, dice:

Carece esta poesía de elementos exteriores y pintorescos; su riqueza está en la depuración de la vida espiritual interior, en la hondura de sus raíces, en la serenidad que de ella trasciende: en la busca, dentro de la propia conciencia, del sentido humano de las cosas. Hay en esta sensibilidad tan lírica una tendencia intelectual y moral que le presta una universalidad. 35

Luis Alberto Sánchez. El profesor y crítico peruano Luis Alberto Sánchez, no siempre muy cuidadoso de la cronología y los datos biográficos, dedicó algunos párrafos a González Martínez en su Nueva historia de la literatura americana ${ }^{36}$ que no es sino una refundición de lo publicado en sus otros manuales de literatura. Des- 
pués de citar la consabida poesía "Tuércele el cuello al cisne...", señala la verdadera importancia de esta poesía:

Prácticamente, con este soneto, quedó dividida la sensibilidad americana entre buhos y cisnes, es decir, entre neorrománticos y neosimbolistas, y modernistas: aquéllos, meditabundos, parcos; éstos, cargados de melódía, como establécían los cánones de Prosas profanas. $\mathbf{3 7}$

El leve error de cambiar la profesión de González Martínez no invalida el fundamental acierto de que el soneto fué la divisa de la poesía post-modernista.

Tal vez influyera en esta discrepancia fecunda, (sigue la cita) la formación intelectual de González Martínez, en su juventud y durante diecisiete años maestro de provincia (subrayamiento del autor) hasta 1911 , en que, a los cuarenta, se incorporó al movimiento de la capital. De ahí, quizá, esta mezcla de lirismo e ironía, patente en todos sus libros: desde Preludios (1903) y Los senderos ocultos (1911) hasta La muerte del Cisne y Jardines de Francia (1915) .. 38

En primer lugar, fuera del año anterior a 1893, González Martínez ejerció el magisterio hasta después de 1915. Estos diecisiete años de que habla Sánchez han sido el período en que ejerció su profesión de médico.

Arturo Torres-Ríoseco. Torres-Ríoseco en su libro de crítica La gran literatura iberoamericana, ${ }^{39}$ después de haber analizado brevemente la obra de González Martínez hasta 1915, otra vez cita la ya consabida frase del reto del buho al cisne:

Porque fué contra las "aves olimpicas" de Darío que González Martínez manifestó su desprecio en el famoso soneto "Tuércele el cuello al cisne" que terminó con las pompas heráldicas del modernismo... 40

resumen. Hemos indicado que los manuales de literatura, en su mayoria, dan una definición incompleta del arte y de la obra de González Martínez. Y aunque existen muchos estudios de su obra, ninguno de ellos puede considerarse como definitivo; unos, por haber sido conferencias o cortos estudios de homenaje, $y$ otros, por ser limitados debido a la fecha de stu publicación. 
Como declaramos antes, nuestro objeto es el de completar este vacío en la crítica de la poesía de González Martínez y el de aclarar esos puntos de crítica que, aunque de buena intención, obscurecen la comprensión profunda del arte de González Martínez. Queremos definir y estudiar su misticismo y su panteísmo, ubicar su actitud de reformador del modernismo, y hacer un estudio más completo.

En carta inédita al autor, fechada en 5 de octubre de 1947, declaró el mismo señor González Martínez:

Los estudios sobre mi obra lírica andan dispersos. Yo opino, como usted, que por muchos y muy interesantes que sean. no existe entre ellos algo esencial y definitivo. Yo espezo que el trabajo de usted repare esta falta, no por la apreciación generosa, sino por la honda comprensión. 41

José M. ToPETE, University of Florida.

NOT A S

1 Frances Benge, La Biografía Lírica de Enrique González Martínez. (México, Universidad Nacional, 1924).

2 Antonio Castro Leal, "Enrique González Martínez", prólogo a Preludios - Lirismos - Silenter - Los senderos ocultos. México. Ed. Porrúa. S. A., 1946).

3 Pedro Henriquez Ureña. Seis ensayos en busca de nuestra expresión. (Buenos Aires, Babel, 1927.) Págs. 101-117.

4 Ibid., pág. 110.

5 Ibid., pág. XI.

6 Alfonso Reyes, prólogo a Los senderos ocultos. (México, Librería de la Vda. de Ch. Bouret, 1918), págs. IX-XXI.

7 Ibid., pág. XI.

8 Ibid., pág. XII.

9 Ibid., pág. $\mathrm{XX}$,

10 Ibid., pág. XIV.

11 Ibid., pág. XIV. 
12 Ibid., pág. XVI.

13 Manuel Toussaint, "Evolución poética de Enrique González Maztínez", estudio en Poemas escogidos. (Barcelona, Maucci, 1917.) Págs. 7-32.

14 Ibid., págs. 30-31.

15 Robert Avrett, "Enrique González Martinez, Philosopher and Mystic", en Hispania, Stanford, 1931, XIV: 18-92.

16 Eduardo Colín, Verbo selecto, (México, Ed. México Moderno, 1922): Luisa Luisi, A través de libros y autotes, (Buenos Aires, 1925); y Emilio Suárez Calimano, 21 Ensayos, (Buenos Aires, 1926).

17 Carta inédita al autor.

18 Enrique Díez-Canedo, prólogo a El rometo alucinado, (Madrid. Ed. Saturnino Calleja, S. A., 1925); E. D. C., "Enrique González Martinez en su Plenitud", en Revista Iberoameticana, vol. II, núm. 4, noviembre 1940 , págs. 383-387; y E. D. C., Letras de América, (México, El Colegio de México, 1944).

19 Enrique Díez-Canedo, prólogo a El romero alucinado, op. cit., pág. 11.

20 Isaac Goldberg, Studies in Spanish-American Litetature, (New York, Bretano's Publishers, 1920), págs. 181-192.

21 Este tema fué desarrollado por Pedro Salinas en un artículo titulado "El cisne y el buho", Revista Iberoamericana, vol. II, núm. 3, 55-57, (1940).

22 I. Goldberg, op, cit., pág. 82.

23 Luis G. Urbina, La vida literatia de México, (Madrid, Imprenta Sáenz, 1917), págs. 285-291.

24 Luis G. Urbina, prólogo a Las señales furtivas, (Madrid, Ed. Saturnino Calleja, S. A., 1925), págs. 9-17.

25 Ibid., pág. 16.

26 R. Blanco-Fombona, El modernismo y los poetas modernistas, (Madrid, Editorial Mundo Latino, 1929), págs. 351-354.

27 Ibid., pág. 353.

28 Carlos González Peña, Historia de la literatura mexicana, (México, Ed. Porrúa, S. A., 1945, tercera edición), págs. 327-329.

29 Ibid., págs. 178-179.

30 Julio Jiménez Rueda, Letras mexicanas en el siglo XIX, (México, Fondo de Cultura Económica, 1944), págs. 177-179. 
31 Ibid., págs. 178-179.

32 Alfred Coester, Anthology of the Modernista movement in Spanish America, (Boston, Ginn and Company, 1924), 314 págs.

33 Ibid., pág. 308.

34 Federico de Onís. Antología de la poesia española e hispanoamericana (1882-1932), (Madrid, Imp. de la Lib. y Casa Edit. Hernando, S. A., 1934, págs. 488-503).

35 Ibid., pág. 489.

36. Luis Alberto Sánchez, Nueva historia de la literatura americana. (Buenos Áres, Editorial Americalee, 1944), págs. 331-332.

37 Ibid., pág- 332 .

38 Loc. cit.

39 Arturo Torres-Ríoseco, La gran literatura iberoamericana, (Buenos Aires, Emecé Editores, S. A., 1945), págs. 127-138.

40 Loc. cit.

41 Carta inédita al autor. Nota.-En septiembre de 1949 se terminó en la Universidad del Sur de California una tesis doctoral titulada "El mundo poético de E. González Martínez" de la cual este estudio es el capitulo II. 